\title{
O Sentido da Velhice para Homens e Mulheres Idosos
}

The Meaning of Old Age for Elderly Men and Women

\author{
Maria das Graças Melo Fernandes \\ Enfermeira. Doutora em Sociologia. Professora do Programa de \\ Pós-graduação em Enfermagem da Universidade Federal da \\ Paraíba. \\ Endereço: Rua Engenheiro Normando Gomes de Araújo, 132, Bessa, \\ CEP 58037-125, João Pessoa, PB, Brasil. \\ E-mail: graacafernandesळhotmail.com \\ Loreley Gomes Garcia \\ Pós-doutorada em Women's Studies. Professora do Programa \\ de Pós-graduação em Sociologia e Programa de Pós-graduação \\ em Desenvolvimento e Meio Ambiente da Universidade Federal \\ da Paraíba. \\ Endereço: Rua Prof Maria Sales, 512, apt 402, CEP 58039-130, João \\ Pessoa, PB, Brasil. \\ E-mail: loreleyळoi.com.br
}

\section{Resumo}

Este estudo de natureza qualitativa foi efetivado no grupo de convivência Juventude Acumulada, do bairro popular de Cruz das Armas, do município de João Pessoa-PB. Da pesquisa, participaram dezoito mulheres e doze homens idosos que aceitaram, livremente, participar da investigação. A coleta de dados foi realizada nos meses de abril e maio de 2008 , mediante uma entrevista semiestruturada gravada. $\mathrm{Na}$ análise do material empírico, utilizamos a abordagem de análise de discurso proposta por Fiorin. No que se refere aos sentidos atribuídos à velhice, verificamos que boa parte dos homens se sentem jovens, "velhos só na idade" ou diante da desvalia social da aposentadoria. Os demais consideram a velhice algo negativo para suas vidas, que ameaça sua autonomia e independência. As mulheres, em sua maioria, expressam e vivem a velhice de modo ambíguo, ou seja, apesar de entenderem a velhice como algo negativo e presente em suas vidas, essa fase do ciclo vital representa, para muitas, uma oportunidade de desfrutar os anos de vida que lhes restam de forma mais livre.

Palavras-chave: Envelhecimento; Velhice; Gênero; Idoso. 


\section{Abstract}

This qualitative study was carried out in the coexistence group Juventude Acumulada, in the popular neighborhood Cruz das Armas, city of João Pessoa (Northeastern Brazil). Eighteen elderly women and twelve elderly men freely accepted to participate in the research. Data collection was accomplished in the months of April and May 2008 through a recorded semi-structured interview. In the analysis of the empirical material, the discourse analysis approach proposed by Fiorin was used. Concerning the meanings attributed to old age, it was verified that many men feel young, "old only in age" or due to the social dereliction that may come with retirement. The others view old age as something negative for their lives, something that threatens their autonomy and independence. The majority of the women, in turn, express and live old age in an ambiguous way, that is, although they understand old age as something negative and present in their lives, this phase of their vital cycle represents, for many of them, an opportunity to enjoy their remaining years of life more freely.

Keywords: Aging; Old Age; Gender; Elderly.

\section{Introdução}

O conhecimento acumulado sobre como as pessoas envelhecem aponta a plasticidade e a diversidade como características fundamentais, mostrando que nem todos vivem o processo de envelhecimento da mesma maneira, uma vez que esse fenômeno está estreitamente relacionado às formas materiais e simbólicas que identificam socialmente cada indivíduo. Assim, não temos somente uma velhice, mas a velhice que o tempo de cada um faz (Mendonça e col., 2008).

Existem vários fatores envolvidos na diversidade e expressão de heterogeneidade em relação à velhice. Dentre eles, os mais básicos estão ligados ao gênero, à família, ao trabalho e às gerações. Considerando o gênero, Motta (2006) salienta que a velhice afeta de modo diferente homens e mulheres. Como sujeitos que viveram processos socializadores muito diversos em seu curso de vida, por mais que tenham, no processo de envelhecimento, experiências que sejam ou aparentem ser comuns à sua idade, a condição de gênero enseja experiências e representações distintas.

Tendo em mente que as relações de gênero permitem contextualizar a velhice masculina e feminina em diferentes contextos sociais, de modo relacional, por onde se tecem subjetividades, e se traçam trajetórias de vida das pessoas diante do envelhecimento, buscamos neste estudo investigar o significado da velhice para homens e mulheres idosas, considerando esse referencial.

\section{Metodologia}

Este estudo de natureza qualitativa foi efetivado no grupo de convivência Juventude Acumulada do bairro popular de Cruz das Armas do município de João Pessoa-PB. Da amostra, participaram doze homens e dezoito mulheres idosos que aceitaram, livremente, participar da investigação. Quanto às características qualificadoras, os idosos pesquisados possuíam idade variável entre sessenta e 83 anos; eram independentes para a realização das atividades básicas da vida diária e tinham baixo nível socioeconômico e instrucional, sendo todos aposentados ou pensionistas. No que se refere à profissão, os 
homens exerceram, principalmente, os seguintes ofícios: agricultor, pedreiro, marceneiro, jardineiro, vaqueiro, vigia, caminhoneiro e outros. Entre as mulheres, apenas sete, assumiram, ao longo de suas vidas, trabalho remunerado, de modo pontual, sendo duas no cenário público e cinco no âmbito privado, exercendo a função de empregada doméstica, não permitindo a configuração de uma identidade profissional para elas, apesar de mencionarem que suas vidas foram de muito trabalho, especialmente com a educação e o cuidado com os filhos.

A coleta de dados foi realizada nos meses de abril e maio de 2008, mediante uma entrevista semiestruturada, gravada, que foi norteada pelas seguintes questões: Quando pensa em velhice o que vem à sua mente? Qual o significado da velhice para o homem (grupo masculino) ou para a mulher (grupo feminino)?

$\mathrm{Na}$ análise do material empírico, utilizamos a abordagem de análise de discurso proposta por Fiorin (2005). Considerando essa perspectiva, a discussão desse material foi relacionada à literatura para ancorar as posições socais nele reveladas. 0 princípio básico desse enfoque é a compreensão de que o discurso é uma posição social, devendo, assim, ser analisado. Segundo o autor (Fiorin, 2005, p. 77), as representações ideológicas são materializadas na linguagem e, assim sendo, "a análise do discurso vai, à medida que estuda os elementos discursivos, mostrando, por inferência, a visão de mundo dos sujeitos inscritos no discurso".

\section{Resultados e Discussão}

No âmbito das entrevistas, ao arguirmos o grupo masculino mediante a questão: "Quando pensa em velhice, o que vem em sua mente?", obtivemos os seguintes sentidos para o fenômeno:

\section{Finitude}

[...] que a pessoa está se acabando devagarinho. $\varepsilon$ o fim da carreira (Sr. D, 74 anos).

\section{Aposentadoria}

[...] aposentadoria não tem jeito! Comigo foi assim: quando passei dos sessenta, eu ainda não tinha dado entrada nos meus papeis, tinha uns problemas pra resolver. Eu era marceneiro e pedreiro, trabalhava nos dois ramos, mas, quando ia atrás de um serviço, me diziam: o senhor é marceneiro! Pedreiro! O senhor é ex! Aí não teve jeito, me aposentei. Fiquei velho, né? (Sr. $B, 70$ anos).

[...] velho e aposentado é a mesma coisa; é como objeto guardado no fundo do armário (Sr. M, 71 anos).

\section{Dependência}

[...] dependência dos outros [...] Incapacidade, precisão de ajuda (Sr. A, (Sr. C, 71 anos).

\section{Medo}

[...] se você não tiver preparado psiquicamente, mentalmente, você tem medo da velhice, sim. Eu vou the dizer uma coisa: ela apavora. $\bar{\varepsilon}$ medo. É o medo de uma doença, de não ser amado; é o medo de perder a capacidade de andar sozinho [...] (Sr. I, 65 anos).

\section{Doença}

[...] quando uma pessoa envelhece, não tem por onde não ter uma dor de cabeça. É uma AVC [Acidente vascular Cerebral]! É um infarto! O sujeito não deixa de ser diabético, de ter pressão alta, tudo isso faz parte de velhice (Sr. G, 73 anos).

No tocante aos sentidos atribuídos à velhice expressos pelas mulheres, observamos:

\section{Mais experiência de vida}

[...] o tempo que já foi vivido (Sra. I, 7o anos)

[...] é sinal que estou vivendo mais, que estou tendo mais experiência (Sra. M, 65 anos).

Medo

[...] medo, mas a velhice é uma coisa que a gente nem pensa, quando dá fé ela chega (Sra. A, 78 anos).

[...] tenho medo, penso em ficar acamada, é disso que tenho medo (Sra. E, 66 anos).

Finitude

[...] o final [...] uma rosa quando está perdendo as pétalas (Sra. D, 69 anos).

\section{Problemas e limitações}

[...] vêm na minha mente muitos problemas. A gente não é mais jovem, não é mais. Tudo muda. Mas, eu vou levando com o poder de Deus [...]. Mas, não falta problema. $\varepsilon$ mais doença, mais desprezo, limitações no corpo (Sra. N, 61 anos). 


\section{Feiura}

[...] na minha mente a velhice é muito feia. A velhice é muito feia! Porque a velhice só tem ruga, canseira, cansaço, o povo enjoa a gente! [...]. $\varepsilon$ uma coisa feia! (Sra. P, 7o anos).

[...] no meu saber, a velhice é uma coisa que vai chegando e vai levando a beleza e a juventude e trazendo feiura (Sra. S, 65 anos).

Na observação dos discursos, identificamos que homens e mulheres evidenciam sentidos comuns para a velhice, como "finitude", "doença" e "problemas e limitações", os quais conduzem ao medo da dependência e da rejeição, tornando a experiência uma situação não desejada.

Essa relação da velhice com estereótipos ligados à degradação biológica a qual serviu, durante anos, para caracterizar o processo de envelhecimento, continua a impregnar o imaginário cultural, legitimando a inter-relação da velhice com a finitude, abordada com maestria por Elias (2001). Isso afeta indivíduos de diferentes níveis socioeconômicos e culturais, pois, como salienta o autor, tanto a velhice como a morte constituem problema dos vivos. Talvez por isso, o Sr. I salienta: "você já imaginou como é difícil se aceitar a velhice!”.

Entre os fatores que levam à dificuldade de aceitação da velhice, esse senhor aponta não só as disfuncionalidades corporais desencadeadas por ela, mas, principalmente, o preconceito social contra o velho.

A gente sofre não só por conta dos problemas, mas pelo preconceito. A juventude não respeita mais ninguém. Olha uma pessoa de sessenta anos e diz: lá vem o velho. $\varepsilon$ o preconceito. $O$ preconceito tem o poder de destruição, de levar a gente a ficar traumatizado. Mesmo que você aceite, tem um " $Q$ " no meio, e esse " $Q$ " no meio é problemático (Sr. I, 65 anos).

Essa situação preconceituosa vivida pelos idosos é formatada a partir da produção ideológica do social, sustentada, em grande parte, pela população jovem, que marca negativamente a experiência do envelhecer à medida que os idosos passam a valer menos nas trocas sociais, evidenciando, assim, a dificuldade dos não velhos na compreensão e solidariedade (entendida como um jogo entre iguais) para com os velhos, conforme enuncia Elias (2001). Dessa forma, o velho, ressentido e deslocado do ambiente social, tenta rejuvenescer para manter-se valorizado, ativo:

Nós temos que ter um meio de evitar isso [a velhicel, não sei como. É assim que penso. Temos que lutar por uma velhice saudável. Nós temos esse direito (Sr. J, 64 anos)

Eu tenho quase uma obrigação de não cansar, se não eu vou me limitar. Para isso, eu me inspiro nos meus trinta anos. Eu já atinei que o corpo acompanha a cabeça (Sr. I., 65 anos).

Nesse cenário, alguns idosos utilizam sua competência comportamental para aderirem à proposta da velhice saudável - modelo normativo de velhice aceito e propalado pela sociedade atual que possibilita a criação de uma identidade nova e positiva para a velhice em que há o estímulo a adoção de práticas, hábitos e linguagem que possam desfazer ou atenuar a associação entre velhice e signos estigmatizantes, como doença, desabilidade, desengajamento e declínio, ocultando, de algum modo, o envelhecer.

Esses idosos anunciam, ainda, resquício de uma visão mecanicista do corpo, em que a cabeça pensando e o corpo agindo, a velhice não encontra lugar. Nesse contexto, decidir e agir representam a manutenção de sua autonomia e de sua independência, faculdades constantemente ameaçadas pela velhice.

Apesar dos sentidos comuns atribuídos à velhice pelos homens e mulheres, verificamos também, em suas falas, significados dissonantes que guardam relação com a condição de gênero dos depoentes. Entre eles, destacamos a "feiura" por parte das mulheres e a "aposentadoria" por parte dos homens.

Quando as mulheres salientam a feiura da velhice, na nossa visão elas estão se referindo ao fenômeno em sua multdimensionalidade, especialmente a sua dimensão física e a social: "a velhice é feia [...] Tem ruga, canseira [...] 0 povo enjoa a gente!”. Esse discurso realça certa aversão ao envelhecimento, presente na nossa época, manifesta, de forma explícita e/ou simbólica, especialmente pelas mulheres, que as culturas narcisistas requerem um corpo que transgrida as fronteiras do tempo, jovem e belo (Trench, 2004). Corroborando isso, Swain (2003, 
p. 7) ressalta: "no escaninho da velhice, a queda da autoestima é proporcional à ênfase dada pelos discursos sociais aos jovens e à juventude, sinônimos de felicidade sucesso, prazer e inclusão".

Diferentemente, o contrário, o feio, aquilo que sobra quando o belo se ausenta, constitui um ataque ao ideal corpóreo tanto individual como coletivo, conforme analisa Feitosa (2004, p. 30-31): "se a beleza se mostra na harmonia e na proporção, a feiura está relacionada à deformidade e à desmedida. Se a beleza é o esplendor da ordem, da simetria e do equilíbrio, a feiura é a instância do caos, da assimetria, do excesso".

Vale salientar que a feiura parece emergir inexoravelmente no processo de envelhecimento. Assim, no imaginário social, a ideia de velhice e beleza parece sempre inconciliável. Nesse contexto, as mulheres idosas, diante o conflito entre o vivido na sua corporalidade e o esperado pela sociedade, encontram na velhice o atributo da "experiência", dando um sentido positivo a essa etapa da vida, o que guarda em si certa ambiguidade, pois, apesar de associarem o fenômeno a "uma rosa perdendo as pétalas", portanto, feio e finito, elas se consideram felizes por terem alcançado a senescência e, ao longo dessa experiência (de importância secundária em nossa sociedade), terem aprendido muitas coisas.

No que concerne à vivência da aposentadoria como um fenômeno anunciador da velhice, ressaltado claramente por um dos idosos ao expor a dificuldade de manter-se ativo após os sessenta anos "mesmo trabalhando em dois ramos, marceneiro e pedreiro", sendo rotulado por um "ex" trabalhador, e, portanto "disfuncional", observamos que essa realidade é bastante comum em nossa sociedade, em que a incorporação de elementos da modernização (a tecnologia da saúde, a tecnologia econômica, a urbanização e a educação em massa) resulta na diminuição do status dos idosos. Nesse cenário, o velho torna-se aquele que já não pode responder aos objetivos do sistema, passa a ser "estrangeiro" no universo social do capital.

Os aposentados, no geral, especialmente os de baixo nível socioeconômico, sem o trabalho a que se dedicaram durante longos anos de suas vidas, quase sempre passam a perceber a ampliação da desigual- dade social diante das dificuldades de refazerem seus projetos pessoais de uma maneira produtiva e socialmente útil (Coutrim, 2006). Como afirma o Sr. B.: "[...] Aí não teve jeito, me aposentei. Fiquei velho, né?". Nesse caso, estar alijado do sistema produtivo quase define inteiramente o "ser velho", criando barreiras impeditivas de participação do idoso em outras dimensões da vida social, "aprisionando-o no fundo do armário”, conforme expressa o Sr. M.

A convergência dessas formações discursivas está incorporada em um sistema de regras, normas e leis criadas e reproduzidas ideologicamente ao longo da história de nossa sociedade, cujo estigma de descartável materializa-se num corpo que, segundo essa visão, não atende mais às exigências produtivas de uma sociedade de consumo que só reconhece o indivíduo na medida em ele produz (Silva, 2008). A aposentadoria concretiza esse limite do corpo, que, como uma mercadoria que tem seu tempo de uso vencido, deve ser retirado de circulação.

Segundo Figueiredo e colaboradores (2007), as características sociais do masculino em uma sociedade que prioriza o capital, a produção e o mundo público para os homens é verdadeiramente algoz com os idosos que, com a aposentadoria, passam a ter como espaço de convivência o recinto privado do lar, trocando a produtividade pela inatividade e vivenciando perdas relativas a doenças e incapacidades.

Assim sendo, o homem idoso, diante da aposentadoria, não tendo a supremacia do espaço doméstico, ainda visto por alguns como socialmente pertencente às mulheres, marcam seus dias de não trabalho pelas lembranças do tempo em que produziam e eram reconhecidos, ou seja, o vazio de atividades que pode se instalar diante dessa realidade não tem compensação na área doméstica (Motta, 2006).

Segundo Crose (1999), embora alguns homens estejam se tornando mais envolvidos com o trabalho doméstico e com a família, há pouca evidência de mudança social importante nos antigos padrões e papéis masculinos, estando a maioria despreparada para lidar com o senso de inutilidade que a aposentadoria pode provocar. A masculinidade ao velho estilo ainda sobrevive entre os idosos. Essa realidade é bem retratada na afirmação do Sr. H: 
[...] no começo da minha vida de aposentado, sentia que atrapalhava a mulher. Queria ajudar, mas não tinha jeito. Hoje já estou mais acostumado. É como diz o ditado: homem em casa só atrapalha (Sr. H, 68 anos).

Apesar disso, considerando-se as novas realidades predominantes no mundo atual, particularmente a do elevado número de idosos que se aposentam com capacidade produtiva, em decorrência da maior expectativa de vida e diante dos pressupostos do paradigma da velhice saudável, emerge, embora de modo incipiente, algumas mudanças com vistas a abordar a aposentadoria não só do ponto de vista econômico, mas também como uma condição psicossocial. Nesse contexto, verifica-se uma preocupação em reconhecer que o indivíduo aposentado pode desempenhar outros papéis socialmente importantes além do de trabalhador.

Para isso, as políticas públicas destinadas aos idosos buscam implementar, embora, basicamente, em espaços sociais considerados guetos (como os chamados grupos ou centros de convivência), atividades que vêm ocupar o tempo livre do idoso de modo construtivo, ajudando-o a melhorar seu estado anímico e a construir um ponto de referência para integração social, conforme expressa o Sr. J:

"[...] esse grupo ajuda os velhos. Aqui a gente se ocupa, faz exercício, conversa, escuta explicações, tudo [...] É uma coisa boa que a gente tem" (Sr. J, 64 anos).

Compreendida a questão ora analisada, buscamos particularizar a vivência do fenômeno velhice, considerando a perspectiva do masculino e do feminino, ao arguirmos os idosos sobre: "Para o homem, qual o significado da velhice?" (grupo masculino) e, "Para a mulher, qual o significado da velhice?" (grupo feminino). Considerando o discurso produzido pelos homens, observamos que parte deles não atribuiu significado para a velhice por não vivenciá-la, conforme podemos identificar nas falas que se seguem:

"[...] pra mim [...] eu me considero jovem, velho só na idade. Eu não me sinto na idade que tenho. Sinceramente, não me considero velho. Não é querendo [...], é porque não sinto essa de velhice" (Sr. A, 69 anos);
“[...] o homem só fica velho quando ele deixa ser dominado pela velhice. Até hoje, eu me domino, não sei o dia de amanhã. É uma coisa de cabeça" (Sr. F, 68 anos).

Analisando as falas mencionadas, verifica-se uma dicotomia vivida no processo de envelhecer em que conflita o que é desejado e o que não é desejado, a aceitação e a negação da velhice. Nesse contexto, alguns idosos negam a experiência, "sendo velhos só na idade”. O corpo é velho, mas o espírito é jovem. Considerando essa crença, a gradação da velhice e da juventude se liquefaz. E, assim, estão de novo no grupo de vencedor - o jovem e belo (Swain, 2003).

Segundo Motta (1999), é difícil reconhecer-se como velho, porque a velhice é sempre associada, muito mais que às propaladas sabedoria e experiência, à decadência física, mental e social. Nesse caso, a modificação desfavorável do indivíduo é socialmente transformada em estigma. Destarte, os idosos que têm saúde e, de certa forma, se sentem participantes do cotidiano, não se sentem velhos. Reconhecem que "a velhice" existe, mas não é aquilo que está neles. "Velho é sempre o outro" (Debert, 1999, p. 45).

Assim, quando esses homens se apresentam como velhos, fazem isso de modo sutil, mostrandose como pessoas ágeis, tomando como referência o universo feminino, o oposto - "não ágil”: “[...] Bom, se pensar no homem e na mulher, eu sei que o homem na velhice éassim mais ágil. Tem mais possibilidade de viver melhor do que a mulher" (Sr. B, 70 anos); "[...] A mulher com sessenta anos já tá acabada. A maioria, né? O homem, não. Com sessenta, setenta, ainda tá na medida, né?" (Sr. H, 68 anos).

Desse modo, ao alcançarem a idade normatizada socialmente como idosa, os homens se vêem com maiores chances de serem jovens. . Afastam-se, então, de possíveis vestígios de fragilidade, ou da possibilidade de serem "dominados pela velhice", evento que pode comprometer seu padrão de masculinidade: forte e dominador, construído socialmente sobre a base biológica.

Nesses discursos, também se opera uma oposição entre mente e corpo, através da qual se instaura uma margem de ação para os idosos de contraposição às mudanças em geral (a nível social e também físico) associadas ao avanço da idade, sugerindo 
a possibilidade, em certo nível, de administração pessoal desse processo. Afinal, ele é uma coisa de cabeça: "[...] Mesmo seu corpo estando velho, você não é obrigado a ter um espírito envelhecido, você pode ter um espírito jovem, um espírito juvenil" (Sr. $\mathrm{H}, 68$ anos).

Pensamos que a concepção de velhice como uma questão de cabeça possa estar relacionada ao senso de controle e o que ele representa no envelhecimento. Segundo Goldstein (2003), o senso de controle se expressa como a tendência de o indivíduo agir e sentir-se como alguém que pode influenciar as várias situações da vida, seja por meio do exercício de habilidades, seja mediante o conhecimento, a imaginação, o desejo ou a escolha. Subsidiados por esse controle, os depoentes lutam para se manter jovens, visto saberem que nossa sociedade foi pensada para pessoas em exercício pleno de suas funções pessoais e sociais.

Para o Sr. L, a experiência da velhice se configura como um misto de alegria e preocupação, mas o importante é aproveitar o resto da energia jovem: "são dois motivos que a velhice traz: é a alegria de ter vivido muitos anos e a preocupação com o fim. Mas a gente precisa não esmorecer, é só trabalhar com o que ainda está jovem”. Esse discurso reifica a ideia de Motta (2002) de que a velhice nunca é um fato total, incorporando-se também nos pressupostos da "terceira idade", os quais permitem pensar a velhice a partir de outros referenciais que não aqueles ligados a "perdas" ou "déficits".

O Sr. G exclui-se dessa realidade e entende a velhice como algo triste e real em sua vida, especialmente por não se sentir apto a viver as experiências de outrora em virtude das limitações desse processo: o homem na idade não tem mais o que fazer. Tudo muda. É parar mesmo! O importante é não pensar [...] Às vezes bate tristeza, mas fazer o quê??

Na observância do posicionamento das mulheres no que se refere ao significado da velhice, verificamos que suas falas consolidam a crença masculina de que a velhice, quando nas mulheres, se apresenta de modo mais negativo, conforme evidencia essa menção:

[...] eu sei que a velhice é quase a mesma coisa. Agora, o homem é diferente numas possibilidades. A mulher tem mais problemas. $O$ homem é mais sofisticado das coisas da vida, mais do que a gente. Digamos assim: a gente tem uma pessoa na família que dá problemas, a gente se preocupa. Já o homem é diferente da gente. O homem parece que é mais difícil perdoar. Eu digo pelo meu marido [...]. Por isso, eu digo que a gente tem o coração mais fraco do que o homem. O homem tem o coração mais duro, mais perverso, mais forte do que a mulher. Por isso, a gente tem mais problemas. A velhice traz muitos problemas pra mulher: é família, é casa, é doença! (Sra. G, 67 anos).

Essa mulher expressa claramente, inclusive tomando como referência seu próprio marido, como as relações sociais de gênero estabelecidas no seu curso de vida deixaram marcas de atributos femininos estereotipados em seu corpo, em seus sentimentos e em seu modo de agir, fazendo-a absorver os problemas da família e da casa por ter um coração pronto para perdoar e se preocupar com o outro (características atribuídas culturalmente à mulher). Nesse contexto, o homem sai de cena e envelhece de modo mais "sofisticado" e com menos problemas e preocupações.

Consubstanciando essa análise, Bassit (2004) salienta que a forma pela qual uma vida é vivida irá refletir nos significados que são atribuídos à velhice, bem como contribuir para o entendimento de uma velhice problemática, com todas as suas disfunções, o que é corroborado pelo discurso que se segue, em que a depoente, diante de tantos problemas, nem sentiu que envelheceu, impossibilitando-a de imputar sentido à velhice, exceto nos seus momentos de solidão:

[...] sabe que eu não sei, porque eu não envelheci, eu não senti, porque minha vida é muito atarefada. A minha casa eu chamo de "Loucacia", porque eu tenho onze filhos, seis noras e cinco genros; então, dá 22 personagens. Todos têm uma coisa pra me contar, o que agrada, o que desagrada, um desabafo, uma vitória. Então, eu me coloco ali pra ouvir. Não dou razão a ninguém, fico entre a cruz e a espada pra não fazer inimigos, entendeu? Minha vida é assim tão atribulada que eu só sinto a velhice à noite na solidão, porque a pessoa que mora comigo chega tarde, dá meia-noite, e eu, só. Rezo o terço, assisto televisão, desmancho uma roupa, faço um ambanhado [...]. Aí, passo a vida e ainda não notei muito (Sra. B, 83 anos). 
Conforme observamos, é nessa "loucacia" da vida que a Sra. B, viúva, assume o papel de conciliadora dos filhos, genros e noras. Apesar de ainda ser respeitada no lócus familiar, principalmente como uma boa ouvinte, ela tem o cuidado de não se posicionar, "fica entre a cruz e a espada" - atribulada, sem lugar. Afinal, deseja a amizade de todos, pois suas relações sociais e de suporte emocional se dão entre eles. A dinâmica de sua vida permite-lhe ficar distante da velhice, sentindo-a apenas quando procura companhia e não acha, quando experimenta a solitária maneira de "ser velho" em nossa sociedade.

Diferentemente da Sra. B, que compartilha sua vida com tantos "personagens", os quais trazem senso de significado e de preenchimento para a sua vida e para a sua velhice, a Sra. E acha a velhice péssima, principalmente pela experiência da solidão determinada pela viuvez, não conseguindo se apropriar do tempo antes despendido ao esposo:

\section{[...] é péssimo: a solidão é muito ruim. Depois da} gente ser casada muitos anos, é péssimo. A gente não sabe mais o que fazer. Nunca me separei do meu esposo, nunca fui usada por outro homem. Quando ele morreu, eu senti muito porque eu não tinha só um esposo, eu tinha tudo. Eu não tinha família, então ele era meu pai, meu tio, meu irmão, ele era tudo. Agora, eu não senti falta do sexo. Eu não tiro essa aliança de jeito nenhum! É minha lembrança (Sra. E, 77 anos).

Essa experiência de viuvez, configurada especialmente pela ideia de incompletude pessoal e social e, portanto, do "ninho vazio", ainda é vivida por muitas mulheres idosas, principalmente por aquelas que, a exemplo da Sra. E, centravam na figura do marido o poder das decisões, bem como seu sentido de pertença: "nunca fui usada por outro homem [...] Ele era meu pai, meu tio, meu irmão, era tudo". Nesse cenário, a lembrança da sua vivência conjugal e da sua expressão sexual talvez tenha ficado perdida: "eu não senti falta do sexo".

A assertiva "eu não tiro essa aliança de jeito nenhum! É minha lembrança”, ancora-se na análise de Motta (2005) de que a viuvez guarda uma condição ambígua e ambivalente - ambiguidade de sentimentos, ambivalência de situação, principalmente para a mulher: não estar mais e, de certo modo, ainda estar casada. Situação representada também pela tradição esquecida de seguir carregando a aliança do morto, o que a identificava como a "viúva de fulano de tal", sem um nome social próprio.

Evidencia-se, então, que a viuvez guarda um forte e especial significado de gênero, não só porque o contrato social fundador da relação perdida, o casamento, emana de situações estabelecidas nessa dimensão da vida social, mas também devido à experiência da viuvez ser diferentemente vivida e representada segundo se trate de homens ou de mulheres, especialmente idosos (Motta, 2005).

No caso do homem idoso, geralmente, a experiência da viuvez transcorre entre a desvalia (helplessness) doméstica e o recurso aos saberes e ajudas de outras mulheres, geralmente do próprio círculo familiar. Com meios próprios de subsistência, a maioria recasa, sem grande demora, quase sempre com mulheres mais jovens do que a esposa anterior.

As mulheres, a exemplo do maior número das idosas participantes deste estudo, bem como das que fizeram parte da pesquisa de Rocha e colaboradores (2005), relataram não querer um novo companheiro, apesar de haver interessados, emergindo também em suas falas o aspecto moral, visto que algumas acreditam que, mesmo que o companheiro tenha falecido, uma mulher não deve ter mais de um homem em sua vida, limitando as oportunidades de relações sexualizadas: [...] o primeiro é o que fica. Muitos já se ofereceram, mas eu não quero nenhum (Sra. N, 61 anos); [...] intenção em homem não tenho mais. Isso não! Homem não fica sem mulher, mas a mulher passa sem homem" (Sra. F, 66 anos).

Vale salientar que essa renúncia de uma relação sexualizada é vivida pela Sra. Q mesmo no âmbito do casamento, pois as sequelas produzidas pelos maustratos do marido fazem-na descrever sua situação civil como "viúva de marido vivo":

[...] eu tenho um marido que só me deu desgosto. Acabou tudo com mulher, me deixou, depois voltou. Aí o sexo nunca mais foi a mesma coisa. Não tenho mais essa sensação com ele. É como se não existisse ninguém. Não quero mais. Já vendi a aliança. Isso não é casamento. $\bar{E}$ como se diz: sou viúva de marido vivo (Sra. Q, 66 anos).

Aprofundando a análise efetivada, ressaltamos que, nos casos em que a mulher foi subordinada a 
partir das regulações primeiras de sua capacidade reprodutiva, é na viuvez e na velhice que ela alcança uma posição mais livre e mais pública, com autonomia e liberdade. Mesmo resignada de algumas perdas, retoma poder para decidir sobre sua vida de forma mais independente, saindo, de algum modo, do "aprisionamento da natureza" socialmente imposto para ressignificar sua história, conforme expressa esse depoimento:

[...] hoje, apesar de velha, eu vivo melhor. Quando eu era mais nova, passei muita perturbação. Casei, ia fazer dezessete anos, com um homem que já tinha quase quarenta anos, ele era viúvo. Aí, eu sofri muito, trabalhei muito. Tive onze filhos. Ele era muito raparigueiro; por onde ele andou, arrumou muita doença pra mim, viu, minha filha? Quase que eu morro. Mas, graças a Deus, faz quase seis anos que ele morreu. Se fosse hoje, essas mulheres jovens de hoje em dia não suportariam o que eu suportei. Hoje, eu tenho problema na circulação, tenho dor nesse braço, mas tô bem, graças a Deus. Tem gente que diz assim: mulher, vocêainda énova, arrume um companheiro. Aíeu digo: Deus me livre! Eu quero sossego. Ele tinha ciúme, tudo. Depois que ele morreu, aí eu disse: agora eu vou à luta (Sra. D, 69 anos).

A senhora D, ao expressar que "essas mulheres jovens de hoje não suportariam o que eu suportei”, fala de mulheres que, de alguma maneira, já superaram importantes desigualdades de gênero. Mulheres que vivenciam ganhos na escolaridade, que entraram maciçamente no mercado de trabalho e que produziram significativas transformações no âmbito da família: casaram-se, descasaram-se, recasaram-se ou não e tiveram menos filhos (Neri, 2007). Para essas, espera-se uma velhice com mais qualidade de vida e independência. Algo que essa senhora só conquistou tardiamente, de modo muito precário,

Com ressalvas importantes à velhice como uma fase da vida em que adveio a liberdade, também foi elaborada essa fala:

[...] para a mulher, a velhice é a melhor fase. Só faço o que quero e quando quero. Antes era obrigação com marido, com filho, com tudo. Hoje, não preciso cuidar de ninguém. No meu tempo de juventude, não aproveitei nada, era presa. Depois casei, aínão deu. Agora, vivo como jovem, graças a Deus, mesmo com pouca saúde. Acabou aquela história de eu ficar em casa o tempo todo (Sra. F, 66 anos).

Conforme verificamos, essa mulher não deixa de referir problemas que julga "da idade", no entanto pode se afirmar como "jovem", porque certas experiências e prazeres referenciados à juventude, ela só estão conhecendo na velhice, quando do alívio, principalmente, do marido autoritário, encontrando na liberdade e no lazer recursos eficazes de resistência e recuperação de contentamentos perdidos no tempo, embora isso exija adaptação e constante autorregulação em termos biológicos psicológicos e sociais.

Esse senso de liberdade das mulheres idosas também é referendado pelo estudo de Motta (2006, p. 8o), em que uma das participantes, de 64 anos, sem marido e sem filhos sob seus cuidados, declara: "meu projeto agora é me soltar por aí, pelo mundo, viajar até num jegue velho, por aí. Eu quero mais é curtir a vida!". Condição que analisaria Simmel (1967, p. 24): "significa mais do que esse direito de "mera liberdade', significa a possibilidade de 'elaboração de um modo de vida". Representa um tempo de realização de sonhos e desejos postergados.

É como se uma "liberdade de gênero" se sobrepusesse, em muitos momentos, à "condição geracional" (Motta, 1999). Vale salientar que a "liberdade" reconhecida pelos homens é bem diferente dessa que entusiasma as mulheres, é a desobrigação do trabalho (público), pois a liberdade de ir e vir, a qualquer hora e lugar, sempre tiveram. A autora ora mencionada (Motta, 1999, p. 212-213) caracteriza a liberdade referida pelas mulheres idosas como estranha:

[...] é uma estranha liberdade, a de todas elas. Estranha, pela dupla valência: como liberdade de gênero, assinala-se positivamente - mulheres que podem circular, viver conforme sua vontade; mas como liberdade geracional e, sobretudo existencial, tem também o sentido do marginalismo: podem sair porque já não importam tanto; já não serão bonitas (velho = gasto, feio), não irão atrair os homens - nem os da sua idade; já não reproduzem, não há muito que preservar. 
Numa abordagem de algum modo congruente com a análise exposta, Attias-Donfut (2004) discorre que a "liberdade geracional" expressa, mais frequentemente, pelas mulheres idosas, decorre do fato de os controles sociais sobre elas serem afrouxados, posto que já não detêm, principalmente, a função procriativa. 0 término das relações profissionais e familiares leva, também, a uma liberação de normas comportamentais sexuadas, vinculadas a esses papéis, conduzindo a idosa a ter mais tempo livre e autonomia para investir em seu crescimento pessoal e no desempenho de atividades centradas na própria satisfação.

Além disso, a maioria delas, que nunca teve remuneração, pois só trabalhavam no lar, com o direito previdenciário universal de benefício vitalício da aposentadoria aos sessenta anos, passou a ter um salário-mínimo mensal que garante autonomia e independência econômica para usufruir bens e serviços que, até então, lhe colocava na dependência do marido e/ou filhos (Figueiredo e col., 2007), permitindo sua autoafirmação no cotidiano.

Esse apoderamento da idosa também pode advir de uma realidade em que ela assume a gestão da casa e das finanças por incapacidade do marido de realizar essas funções:

[...] meu marido era carrasco. Hoje, teve um aneurisma, aí tá brando. Agora, quem manda sou eu. Quando ele dá um gritinho, eu não aceito, já levei muito grito. $\varepsilon$ tem mais! O dinheiro é na minha mão. Eu agora decido o que é pra fazer (Sra. R, 64 anos).

Nesse contexto, inverte-se a crença popular, e o verdadeiro sexo frágil passa a ser o masculino. A mulher, outrora oprimida, agora ocupa lugar ativo no sistema de opressão: grita e decide unilateralmente.

Em alguns casos, a possibilidade de autoafirmação da idosa produzida, em especial, pela melhoria de suas condições econômicas nem sempre se concretiza, pois essas condições por si não são capazes de neutralizar a rejeição, a discriminação e o preconceito em relação ao idoso nos diferentes níveis sociais, especialmente em nível familiar: $\mathrm{Na}$ velhice, os filhos querem mandarna gente; aí, eu não aceito. Aí eu digo: ainda tô viva! Ainda tô viva! Eles pensam que a gente não sabe fazer mais nada" (Sra.
S, 65 anos); "A velhice é muito triste. A pessoa não tem a atenção dos filhos, tudo o que a pessoa fala aborrece, ignora a gente de tudo" (Sra. Q, 66 anos).

Do mesmo modo, é comum a pessoa idosa se sentir violentada ao perceber que os seus familiares apresentam mais interesse em usufruir de seus recursos econômicos do que o desejo de tratá-la com dignidade, conforme podemos verificar nos termos do depoimento da Sra. J, em que a velhice e o velho são associados, respectivamente, ao desprezo e a um objeto inútil: [...] a velhice para mim é desprezo, cansaço, doenças e aborrecimento da família e dos demais. O velho por si só já é um objeto inútil, sem nenhum proveito. Do velho a família só quer o dinheiro e mais nada. Perdoa-me a franqueza!" (Sra. J, 73 anos).

A violência contra os idosos se expressa de maneira variada nos níveis individual, familiar, institucional, comunitário e em âmbito nacional e internacional. Porém, é no interior das famílias que ela ocorre de modo mais pronunciado, pois é nesse cenário em que mais veementemente os valores "arcaicos", condicionados historicamente e cristalizados pelas pessoas mais velhas, são questionados pelos mais jovens, ameaçando relações de poder outrora estabelecidas e, consequentemente, gerando conflitos intergeracionais.

Embora a violência familiar que vitima os idosos seja apresentada como de indiscutível presença, Menezes (1999), bem como Sanches, Lebrão e Duarte (2008), ressaltam outras duas questões que disputam com ela um espaço de relevância: em primeiro lugar, um tipo de negligência social difusa que se manifesta pela omissão por parte da sociedade civil e do Estado no que se refere à implementação de políticas e de programas de atenção ao idoso que supram suas necessidades de maneira eficaz; em segundo lugar, como uma derivação dessa negligência, assinala-se a violência institucional, cuja maior expressão são os asilos de idosos, onde são comuns processos de maus-tratos, de despersonalização, de destituição de poder e vontade, de falta ou inadequação de alimentos e de assistência à saúde.

Considerando o gênero, estudos efetivados por Figueiredo (1998) e Jatobá e colaboradores (2004) apontam que a violência intrafamiliar contra os idosos incide mais frequentemente sobre as mulheres, 
as quais são vítimas de todas as formas de maustratos - algumas delas se expressam neste estudo por meio da fala da Sra. J - tais como, psicológico/ verbal, negligência (a velhice para mim é desprezo), conflitos familiares (aborrecimento da família), uso indevido da aposentadoria ou exploração financeira (do velho a família só quer o dinheiro e mais nada) e agressão física.

Outra forma de violência praticada contra as mulheres participantes deste estudo constituiu a exploração das suas atividades, o que as faz vivenciar essa etapa da vida com grande sobrecarga física e psicológica, traduzindo a velhice como "algo que atrapalha”, que limita a agilidade necessária para que elas possam fazer diante das demandas de atividades domésticas que lhes são requeridas.

[...] assim, como a gente tem os fazeres de casa, a velhice sempre atrapalha. Tem neto, às vezes, as filhas trabalham, e o neto fica com a gente. Tudo isso é mais problema na velhice. É mais preocupação porque nosso corpo já tá mais devagar, mais dolorido, e, às vezes, a gente não consegue dar conta das coisas [...] (Sra. C, 70 anos).

A velhice da mulher é difícil. A gente cuida dos filhos; aí depois vêm os netos, é muito trabalho. Ninguém se importa, sozinha não tenho como mudar nada. Tudo é nas minhas costas: lavar, passar, cozinhar. Quando termino, o corpo dói. Dói tudo, fica sofrido (Sra. Q, 66 anos).

Esse achado também foi verificado em outras pesquisas, como as realizadas por Fernandes (2003) e por Gondim e Costa (2006), as quais identificaram que muitas mulheres, ao tornarem-se avós, são designadas para cuidar dos netos, quando suas filhas, jovens e inexperientes, precisam trabalhar, transformando essa tarefa que, comumente, seria uma atividade prazerosa, numa responsabilidade desencadeadora de desgaste, especialmente por elas estarem mais predispostas ao impacto negativo do cuidado devido às mudanças associadas ao próprio envelhecimento, às doenças e aos desconfortos próprios da idade, bastante aludidos em seus discursos: meu corpo tá mais devagar, mais dolorido [...]". Quando termino, o corpo dói. Dói tudo, fica sofrido (Sra. Q).

O conteúdo do discurso da Sra. Q nos faz perceber ainda que mudanças no curso de sua vida nem sempre dependem apenas da iniciativa individual ou da própria vontade, mas de ações dos outros ou de fatos que lhes permitam, ou seja, estão intimamente vinculadas a terceiros, dependentes dela ou dos quais ela depende, "que não se importam". Isso torna sua velhice difícil.

\section{Considerações Finais}

No que se refere aos significados que os idosos imprimem à velhice e à sua experiência diante do envelhecimento, eles estão impregnados mais por um esforço de manutenção dos atributos que lhes são postos socialmente do que por uma busca de novas aquisições. Vale ressaltar que mesmo num grupo, de algum modo possuidor de características homogeinizadoras como a condição geracional, a de renda, e mesmo no âmbito de um gênero particular (homem ou mulher), observamos que o discurso dos informantes desta pesquisa evidencia a heterogeneidade da velhice e do "ser velho", presente tanto em seu imaginário como em sua vivência.

Para os homens, a velhice, como fenômeno universal, significa "aposentadoria", "dependência", "doença" e "finitude". Por isso, amedronta. Destarte, quando convidados a expressarem o sentido da velhice para si, alguns deles ressaltaram que esse evento não alcançou suas vidas, especialmente no plano simbólico, pois, apesar de a idade cronológica os situar na faixa etária convencionada socialmente como idosa, bem como limitar o exercício de seus papéis sociais no sistema produtivo em decorrência da aposentadoria, eles ainda se consideravam jovens, uma vez que perceberam a velhice como um "estado de espírito", escamoteando o fenômeno na esfera da subjetividade.

Os demais idosos, ao particularizarem a questão, consideram a velhice um fenômeno "ameaçador" para sua corporeidade, por isso, no geral, buscam resistir, engajando-se, particularmente, nos pressupostos da velhice ativa e saudável, talvez na tentativa de encontrar uma "máscara" que agrade a si e aos todos, em que as marcas corporais produzidas pela ação do tempo sejam atenuadas diante da expressão de uma competência comportamental que lhes permita transitar como velhos, porém com sua autonomia preservada e com maior aceitação social.

Em se tratando das particularidades reveladas 
pelas mulheres idosas no que se refere ao significado da velhice, elas expressaram e experimentaram o fenômeno de modo ambíguo, ou seja, apesar de entenderem a velhice como algo negativo (problemas e limitações, dependência, finitude, feiura, medo) e presente em suas vidas, algumas, mesmo limitadas por dificuldades sociais (abandono, violência) e por alterações na saúde, consideram essa idade como aquela em que a experiência é seu atributo principal, ou ainda aquela que oferece uma oportunidade para elas desfrutarem os anos de vida que lhes restam de forma liberta e mais positiva, pois já venceram o processo de subordinação imposto pelos maridos autoritários e violentos, seja em decorrência da viuvez, seja em consequência da elaboração de um novo modo de ser e de viver.

Nesse processo de reconstrução de um novo sentido para suas vidas na velhice, as mulheres viúvas, em sua maioria, não incluem a busca de um novo parceiro, pois a vivência de sua sexualidade e afetividade no casamento foi desprovida de prazer, centrada especialmente na reprodução e na submissão de sua corporalidade, como mulheres casadas e obedientes. Essas memórias apagam seu interesse de estabelecerem novas relações afetivas.

Vale salientar que, na abordagem da velhice na perspectiva de gênero, outras variáveis se encontram interpostas e, como tal, influenciam a natureza do processo de envelhecimento de homens e mulheres, isto é, o sexo, as características hereditárias, o grau de educação, o status, a cultura e a profissão também são condições que permeiam a individualidade da pessoa idosa, não permitindo, assim, que se estabeleça um modelo padrão para a experiência da velhice. Há, assim, a "bricolagem” de diferentes modelos de vivência desse fenômeno.

\section{Referências}

ATTIAS-DONFUT, C. Sexo e envelhecimento. In: PEIXOTO, C. E. (org.). Família e envelhecimento. Rio de Janeiro: FGV, 2004. p. 89-105.

BASSIT, A. Z. Na condição de mulher: a maturidade feminina. In: PY, L. et al. (org.). Tempo de envelhecer: percursos e dimensões psicossociais. Rio de Janeiro: NAU Ed. 2004. Cap. 6, p.137-157.
COUTRIM, R. M. da E. Algumas considerações teóricas e metodológicas sobre estudos de sociologia do envelhecimento. Revista Brasileira de Geriatria e Gerontologia, Rio de Janeiro, v. 9, n. 3, p. 17-30, jan. 2006.

CROSE, R. Por que as mulheres vivem mais que os homens? E o que eles podem aprender com elas. Rio de Janeiro: Rosa dos Tempos, 1999.

DEBERT, G. G. A reinvenção da velhice: socialização e processos de reprivatização do envelhecimento. São Paulo: FAPESP, 1999.

ELIAS, N. A solidão dos moribundos. Seguido de envelhecer e morrer. Rio de Janeiro: Zahar, 2001.

FEITOSA, C. Alteridade na estética: reflexões sobre a feiúra. In: KATZ, C. S.; KUPERMANN, D.; MOSÉ, V. Beleza, feiúra e psicanálise. Rio de Janeiro: Contra Capa Livraria, 2004. p. 29-38.

FERNANDES, M. das G. M. Tensão do cuidador familiar de idosos dependentes: análise conceitual. 2003. Tese (Doutorado em Ciências da Saúde) - Universidade Federal da Paraíba, João Pessoa, 2003.

FIGUEIREDO, S. C. S. Abuso de pessoas idosas na família: um ensaio. Gerontologia, São Paulo, v. 6, n. 3, p. 126-135, 1998.

FIGUEIREDO, M. do L. F. et al. As diferenças de gênero na velhice. Revista Brasileira de Enfermagem, Brasília, n. 6o, v. 4, p. 422-427, jul./ ago. 2007.

FIORIN, J. L. Elementos de análise do discurso. 13. ed. São Paulo: Contexto, 2005.

GOLDSTEIN, L. L. No Comando da própria vida: a importância de crenças e comportamentos de controle para o bem-estar na velhice. In: NERI, A. L.; FREIRE, S. A. (org.). $\varepsilon$ por falar em boa velhice. 2. ed. Campinas: Papirus, 2003. Cap. 3, p. 55-68.

GONDIN, R. M. F.; COSTA, L. M. Violência contra o idoso. In: FALCÃO, D. V. da S.; DIAS, C. M. de S. B. (Orgs.). Maturidade e velhice. São Paulo: Casa do Psicólogo, 2006. Cap. 8, p. 169-191.

JATOBÁ, M. B. et al. A repercussão do estatuto do idoso nas denúncias de maus-tratos. A Terceira Idade, São Paulo, v. 15, n. 31, p. 38-53, set. 2004. 
MENDONÇA, R. T. et al. Medicalização de mulheres idosas e interação com consumo de calmantes. Saúde e Sociedade, São Paulo, v. 17, n. 2, p. 95-106, abr./jun. 2008.

MENEZES, M. R. Da violência revelada à violência silenciada: um estudo etnográfico sobre a violência doméstica contra idosos. 1999. Tese - (Doutorado em Enfermagem) Escola de Enfermagem de Ribeirão Preto, Universidade de São Paulo, Ribeirão Preto, 1999.

MOTTA, A. B. As dimensões de gênero e classe social na análise do envelhecimento. Cadernos Pagu, Campinas, n. 13, p. 191-221, 1999.

MOTTA, A. B. Envelhecimento e sentimento do corpo. In: MINAYO, M. C. de S.; COIMBRA JÚNIOR, C. E. A. (Org.). Antropologia, saúde e envelhecimento. Rio de Janeiro: FIOCRUZ, 2002. Cap. 2, p. 37-50.

MOTTA, A. B. Viúvas: o mistério da ausência. Estudos Interdisciplinares sobre o Envelhecimento, Porto Alegre, v. 7, p. 7-24, 2005.

MOTTA, A. B. Visão antropológica do envelhecimento. In: FREITAS, E. V. et al. (Org.). Tratado de geriatria e gerontologia. 2. ed. Rio de Janeiro: Guanabara, 2006. Cap. 8, p.78-82.

NERI, A. L. Feminização da velhice. In: NERI, A. L. et al. (Org.) Idosos no Brasil: vivências, desafios e expectativas na terceira idade. São Paulo: Fundação Perseu Abramo, 2007. p. 47-64.
ROCHA, C. et al. Como mulheres viúvas de terceira idade encaram a perda do companheiro. Revista Brasileira de Ciências do Envelhecimento Humano, Passo Fundo, v. 2, n. 2, p. 65-73, jul./dez. 2005.

SANCHES, A. P. R. A.; LEBRÃO, M. L.; DUARTE, Y. A. O. Violência contra idosos: uma questão nova? Saúde e Sociedade, São Paulo, v. 17, n. 3, p. 9o-10o, jul./set. 2008.

SILVA, L. R. F. Da velhice à terceira idade: o percurso histórico das identidades atreladas ao processo de envelhecimento. História, Ciências, Saúde - Manguinhos, Rio de Janeiro, v. 15, n. 1, p. 155-168, jan./mar. 2008.

SIMMEL, G. A metrópole e a vida mental. In: VELHO, O. G. (Org.). O fenômeno urbano. Rio de Janeiro: Zahar, 1967.

SWAIN, T. N. Velha? Eu? autoretrato de uma feminista. LABRYS: estudos feministas, n. 4, ago./ dez. 2003. Disponível em: <http://vsites.unb.br/ ih/his/gefem/labrys4/textos/anahi1.htm>. Acesso em: 09 jun. 2008.

TRENCH, B. Saúde da mulher. In: LITIVOC, J.; BRITO, C. Envelhecimento: prevenção e promoção da saúde. São Paulo: Atheneu, 2004. Cap. 13, p. 189-202. 